University of Nebraska - Lincoln

DigitalCommons@University of Nebraska - Lincoln

$12-2003$

\title{
Common Questions about AAC Services in Early Intervention
}

Cynthia J. Cress

University of Nebraska-Lincoln, ccress1@unl.edu

Christine A. Marvin

University of Nebraska - Lincoln, cmarvin1@unl.edu

Follow this and additional works at: https://digitalcommons.unl.edu/specedfacpub

Cress, Cynthia J. and Marvin, Christine A., "Common Questions about AAC Services in Early Intervention" (2003). Special Education and Communication Disorders Faculty Publications. 88.

https://digitalcommons.unl.edu/specedfacpub/88

This Article is brought to you for free and open access by the Department of Special Education and Communication Disorders at DigitalCommons@University of Nebraska - Lincoln. It has been accepted for inclusion in Special Education and Communication Disorders Faculty Publications by an authorized administrator of DigitalCommons@University of Nebraska - Lincoln. 


\title{
Common Questions about AAC Services in Early Intervention
}

\author{
Cynthia J. Cress and Christine A. Marvin \\ University of Nebraska-Lincoln, Lincoln, Nebraska, USA \\ Corresponding authors - Cynthia Cress \& Chris Marvin, 202 Barkley Memorial Center, \\ University of Nebraska-Lincoln, Lincoln, Nebraska 68583-0732, USA; \\ tel 402 472-3956, fax 402 472-7697, email ccress1@unl.edu or cmarvin1@unl.edu
}

\begin{abstract}
Children and adults with developmental delays have benefited from the use of augmentative and alternative communication (AAC) systems to develop language skills necessary for more generative and functional communication. Beginning communicators however, have historically been considered too young or too pre-linguistic and therefore have not been introduced to AAC systems until behaviors, thought to be prerequisites, have been noted. Recent research and theories about early communication development have challenged this traditional practice and broadened the scope of what is considered to be AAC. Practitioners and parents unfamiliar with early AAC options may not recognize possible applications of communication strategies used with typically developing children and older persons with developmental disabilities. AAC is applicable at all ages for learning communication roles and behaviors as well as for functional communication for persons who do not yet demonstrate clear referential symbol use. This article addresses nine questions that are frequently asked about early introduction of AAC systems to children under 3 years of age. Rationales and strategies are provided that can assist early interventionists and parents in considering AAC options for children at risk for being unintelligible or non-speaking.
\end{abstract}

Keywords: augmentative and alternative communication, children, early intervention, prelinguistic, symbol, gesture, vocalization, interaction speech

\section{INTRODUCTION}

Access to augmentative and alternative communication systems (AAC) has been demonstrated as a means to acquire some of the necessary prelinguistic and cognitive skills that are essential for language development (Brady, 2000; Light, Collier, \& Parnes, 1985; Romski \& Sevcik, 1996). Early access to multiple forms of AAC is essential for early communication development in young children at risk for expressive communication impairments. Knowledge of how to facilitate the transition from pre-linguistic to linguistic means of communication in any mode, however, may be limited for many professionals (Wetherby, Warren, \& Reichle, 1998). Early interventionists may struggle to understand how to prioritize and foster key emerging behaviors in children who use multiple augmented modes of communication. Also, family and professional attention to medical and physical interventions in the early years of life for high-risk populations of children may take priority over communication systems. Despite all good intentions to address oral-motor and feeding needs, positioning and seating, play and cognitive development experiences, and parent training for maximizing communicative opportunities with the children's existing modalities, too many children may move on to the preschool years with underdeveloped, limited communication repertoires and restricted access to formal AAC modes.

Recent publications have highlighted key issues in the application of AAC for beginning communicators, both children 0-3 years old and older children, and adults who are developing communication skills typical of that age group (Reichle, Beukelman, \& Light, 2002). AAC includes a progression of communication skills from early behaviors to symbolic 
and technological skills, and can involve enhancing non-symbolic modes as well as vocal, unaided, and aided symbolic modes (see Siegel \& Cress (2002) for a more thorough introduction to early AAC strategies). Communication strategies described for intervention with older children and people with developmental disabilities can also be applied to early AAC programs. Research has demonstrated success in applying AAC interventions introduced to children aged from 3 to 8 years (e.g., Culp, 1989; Goossens', 1989; Light et al., 1985; Romski et al., 2001). Successful AAC use has also been noted for older individuals who present with cognitive skills in the 18 to 36 month range (Brady et al., 1995; Gobbi et al., 1986; Romski \& Sevick, 1996). Many of these strategies are often applicable to children under 3 years of age who are beginning communicators and at risk for being unintelligible or non-speaking.

Although best practice for people with expressive impairments involves availability of AAC strategies at all ages and skill levels (ASHA, 1991), many misconceptions or perceived limitations may lead practitioners to judge that a child is not ready for AAC. First, practitioners may not fully appreciate the breadth of communication behaviors involved in an AAC system, including "an integrated group of components, including the symbols, aids, strategies, and techniques used by individuals to enhance communication" (ASHA, 1991, p. 10). Because a child does not yet use a particular AAC technology does not preclude more direct behavioral AAC strategies for that child with or without formal AAC devices. Many practitioners may unknowingly be implementing AAC in their early interventions, if they already prompt natural communication signals, for example, or adapt environments to increase communication opportunities for children with expressive impairments. In the present paper, we reflect the ASHA standard definition of AAC and emphasize that AAC includes all augmentation options, including behavioral adjustments of the listener as well as non-vocal behaviors, gestures, and physical devices used by the child (e.g., Beukelman \& Mirenda, 1998; Vanderheiden \& Lloyd, 1986). As an example, a parent might learn to recognize and respond differently to spontaneous behaviors produced by a young child with disabilities, within the scope of AAC service delivery, as well as learn to promote additional communication behaviors and gestures.

Practices and other common misconceptions about early AAC that may lead to inappropriate exclusion of very young children from AAC services are listed below.
(1) Postponing AAC until there is a consistent delay in verbal communication over time (the "wait and see" strategy), rather than maximizing communication across all available modes throughout the early childhood years.

(2) Presuming that AAC is "giving up" on some forms of communication rather than a means of enhancing and complementing all forms of communication.

(3) Restricting AAC services to complete technological or symbolic forms rather than recognizing that the development of symbolic and technical skills proceeds along a gradual continuum for all children.

(4) Judging that a child has "failed" at AAC after implementing a limited set of strategies, rather than adapting the range of functions, activities, and partner supports that are needed for all communicators to be successful.

(5) Separating other early intervention services from AAC services rather than recognizing the essential relevance of communication development for children across all service disciplines.

(6) Assuming that young children cannot develop the successful skills demonstrated by older persons with complex communication needs, rather than recognizing that common strategies are available for all beginning communicators regardless of age.

In this article, we address nine common questions often posed by parents and professionals about the use of AAC for children under 3 years of age. The answers reflect pertinent literature in AAC and are provided to increase understanding of the importance and feasibility of AAC intervention for beginning communicators. Our aim is to clarify early AAC practice issues for parents and practitioners who are new to AAC, as well as more experienced practitioners who provide early intervention and partner training services. The questions and responses are also appropriate for beginning communicators of all ages, including adults with complex communication needs. A brief summary of the nine questions and responses to these questions is provided in Appendix A.

\section{How Early Can AAC Interventions Begin? What Prerequisites are Necessary?}

Children's natural actions and behaviors are the only prerequisites to AAC. Communication starts at birth, with interaction opportunities and the earliest behaviors of children, regardless of the communicative mode. All children first communicate through 
spontaneous behaviors in response to their internal state or environment and the corresponding interpretation of those behaviors by someone in their environment. Although not all children at this basic level of communication produce the same types of signals, such as facial grimaces, cries and other vocal signals, children in alert states will produce detectable reactions to some types of stimuli in the environment. This type of communication is considered to be partner-perceived communication, since the child's spontaneous acts are given communicative significance by the listener/observer (Wilcox, Bacon, \& Shannon, 1995). Even infants in neonatal intensive care units produce signals of stress and comfort, such as eye widening and body tension (Billeaud, 1998), and caregiver responsiveness to these signals may be a type of partner-perceived and partner-augmented communication, critical for children's survival and continued development. When children's earliest communication behaviors are difficult to interpret, the child's need for AAC intervention begins.

Early attempts to assign prerequisites to AAC indicated consideration of symbolic forms of communication only. Shane and Bashir (1980), for example, proposed the cognitive prerequisites of Piagetian Stage V or VI sensorimotor skills for successful use of AAC. These benchmarks were derived from hypotheses that means/end behaviors (Stage V) are necessary but not sufficient for intentional communication, and that representational behaviors (Stage VI) are necessary prerequisites for symbolic communication. Although Shane and Bashir proposed a cognitive age of 18 months as a turning point for competence and control of AAC aids, no formal tests have linked this level of cognitive ability to AAC techniques or equipment (Beukelman \& Mirenda, 1998). Kangas and Lloyd (1988) challenged the notion that cognitive development necessarily precedes related language development, even in typical communicators, since communicative experience can also be a vehicle for expanding cognitive skills. Kangas and Lloyd emphasized the many ways in which augmented strategies, such as developing movement patterns to signal specific activities or using hand signals to request MORE can often precede the development of more formal and symbolic strategies.

Experienced AAC professionals might presume that it is universally understood that there are no prerequisites to AAC, given the wealth of research and clinical experience supporting this view. A tendency in some practitioners to take a restricted view of AAC, however, still can lead to assumptions of entrance skill requirements for AAC assessment and in- tervention. As recently as 2003, professional magazines in speech - language pathology have published checklists of arbitrary skills that were reported to be necessary before implementing AAC (Gur-Arie, 2003). In AAC service delivery, early interventionists still need to beware of hidden prerequisites or any suggestion that a particular child is not ready for AAC. As an example, a child who cannot independently hit a switch or who is not yet an intentional communicator might not be referred for AAC services if practitioners do not recognize that learning these skills is part of AAC service delivery, not a prerequisite to being qualified for AAC.

The earliest AAC intervention can apply to a child's behaviors, gestures, cooperative actions, and sounds, as well as a partner's adjusted perception of meaning assigned to those behaviors (Dunst \& Lowe, 1986). AAC does not depend upon controlling complicated systems or devices. Early behaviors and skills facilitate the gradual development of more complex communication skills, including language (Cress, 2002). Teaching parents to adapt their responses to their children's communication signals, for example, can be considered AAC. Parents of children with delayed or abnormal movement and vocalization patterns may need considerable assistance in recognizing and responding differentially to their child's random or consistent but unconventional signals (Wilcox et al., 1995). Intentional communication, therefore, is based on experiences with pre-intentional behaviors and environmental responses, and if these behaviors or responses are not sufficient to prompt further development, augmentation strategies (i.e., AAC) may be justified at any age or cognitive level.

\section{Will the Use of AAC Interfere with a Child's Vocal Development?}

Published literature and clinical experience supports the assertion that AAC does not interfere with a child's natural ability to develop vocal/verbal communication. Children tend to use the quickest, most effective, and most accessible means available to communicate their wants and needs (Mirenda, 1998). Speech is inherently portable, flexible, and individualized, and is the most likely communication method to achieve a response from a wide variety of listeners, given the predisposition of adults to respond to verbal output from children (Locke, 1996). Even children with limited sound repertoires tend to use those sounds for specific purposes, such as obtaining attention, and parents of non-speaking chil- 
dren can discriminate between different types of vocalizations produced by their child (Hanzlik, 1990; McCune, Kearney, \& Checkoff, 1989). Speech tends to be a communication method preferred by both people relying on AAC and their communication partners, if it is available to the person using AAC and intelligible to listeners (Cumley, 1997; Lasker \& Bedrosian, 2000).

Available research indicates that AAC may actually facilitate vocal communication by increasing interaction, language skills, and/or providing a voice output model for speech. In a recent meta-analyses of 25 published research studies between 1975 and 1998, Millar, Light, and Schlosser (2000) found 50 of the 69 participants studied showed an increase in speech production (number of words and/or vocalizations) following AAC interventions; only two of the participants showed a decrease in speech use. The participants in these studies had significant speech impairments (unintelligible or non-speaking) and included persons with intellectual disabilities (45\%), autism (23\%), multiple disabilities (23\%), and cerebral palsy or unknown diagnosis (9\%). AAC interventions used as independent variables in the studies included sign language (76\%), aided AAC without speech output (16\%), and a combination of AAC approaches (8\%).

Romski, Sevcik, Reumann, and Pate (1989) found that children who received naturalistic modeling and prompting to use a communication board also increased their level of vocal responding. Glennen and McPartland (1999) also reported that five of nine nonspeaking children in their study developed some speech ability after AAC implementation, while 10 of the total 24 children who were studied improved their functional speech abilities. In fact, sign language instruction may, in some cases, facilitate speech production more effectively than speech-only training. In his study of 12 nonspeaking children, Kahn (1981) found that children who received training that focused on sign language in the context of total communication learned more spoken words during the training period than children who received specific vocal training alone. He concluded, “... if sign language is presented in a total communication format, it does not hinder the development of speech. In fact, the learning of sign language may help the child who is having difficulty learning to speak learn to communicate and even develop speech" (Kahn, 1981, p. 118). Also, for children and adults with intellectual disability who are at risk for delays or long-term difficulty with oral communication, sign language has been demonstrated to be effective at prompting vo- cal speech development as well as overall communication development (McIlvane, Bass, O'Brien, Gerovac, \& Stoddard, 1984).

Furthermore, introduction of an AAC system has not been associated with a loss or inhibition of speech development, even in children who have focused difficulties with speech production. Cumley (1997) found that children aged 3 to 7 years with motor speech impairments did not decrease their use of speech after the introduction of formal AAC devices into communicative interactions. Instead, the young children with the most severe impairments substituted picture board selections for some gestures in order to facilitate the resolution of communication breakdowns. Children with less severe expressive impairments continued to rely primarily on spoken language and gestures whenever appropriate, and referred to AAC devices only as necessary to clarify or resolve breakdowns. In other words, these young children were able to use AAC appropriately to supplement their speech, and they did not use AAC to avoid difficult speech behaviors if their speech could be intelligible to listeners.

Using augmentative communication is not an indication of giving up on vocal communication, and neither parents nor therapists should perceive it this way. Because AAC includes all communication methods, intervention also addresses improving functional vocal/verbal skills. Modeling of AAC strategies typically includes providing a verbal model for the message, such as saying more while reinforcing a child's spontaneous signal to continue an activity (Reichle, York, \& Sigafoos, 1991). Voice output of some communication devices can also provide selfgenerated spoken models that children can imitate as they are able. In addition, AAC intervention can incorporate strategies for promoting children's deliberate control and variation of vocalizations toward improving speech in addition to other communication modalities (Cress \& Ball, 1998).

\section{Will This Child Talk?}

Current research and clinical experience has not provided absolute criteria for predicting a child's long-term speech skills, and this question cannot be answered with a simple yes or no when parents or professionals raise it. Practitioners can explain, however, the wide variety of speech sounds that can be used for communication and they can describe how to improve a particular child's use of his or her vocal and/or verbal repertoires. The issue is not one of whether a child will or will not talk; labeling a child 
as "non-speaking" (a term that has frequently been used clinically and in the literature) does not indicate that he or she cannot use speech for any type of communication. A child might not be fully intelligible to all listeners, yet will use speech meaningfully for some people or some purposes. The term non-speaking in fact covers a wide range of spoken abilities, ranging from the use of vocalizations primarily for signaling emotions, to reliance on speech with communication aid support needed only to resolve communication breakdowns (ASHA, 1991). Communicators will rely on AAC if their speech is inadequate to meet their communicative goals, but speech will tend to be a component of most multimodal AAC systems (Cress \& Ball, 1998; Light, Roberts, DiMarco, \& Greiner, 1998; Mar \& Sall, 1999). An interventionist's responsibility is to help the child make optimum use of those vocal and speech skills for communicative effectiveness as part of a multimodal AAC system.

Children who have difficulty controlling muscles involved in the speech/respiratory process, however, or who have other neurological or cognitive limitations that affect speech production, are at risk for not developing speech that is intelligible to all listeners. The more severe the motor limitations, particularly in initiating and controlling fine oral/ vocal movements, the more likely that children will experience continued difficulty in controlling the fine coordinated movements necessary for speech (Bradford \& Dodd, 1996; Levin, 1999). Also, while children who are slow to develop understanding of the symbolic representation of ideas may have limited speech, they do have a wide range of functional vocal communication or verbal output that is not linguistically based (Cress, 2002). The most common indicators of concern for vocal speech development include (a) neuromotor difficulties related to speech and language development, (b) delayed onset of vocalization and/or speech relative to peers, (c) feeding difficulties or persistent oral/motor control problems, and (d) birth or developmental conditions that are associated with ongoing difficulties in vocal development (MacDonald, 1980).

Although some adults who use AAC may have a limited range of sounds, children's motor systems are still developing in ways that cannot be predicted, and early intervention may prove beneficial in maximizing a child's limited vocal repertoire for eventual speech. Almost all children who can vocalize will use sounds in some ways that are interpretable to listeners. It is possible to build upon those vocalizations to make them more useful in accomplishing communicative purposes. Early communication intervention may address children's intentional use of sounds to communicate messages. Early speech intervention can also provide practice in controlling and diversifying children's vocalizations and can increase the child's potential range of vocal signals that can be used for intentional communication. According to Cress and Ball (1998), ways in which vocal skills may be promoted in pre-linguistic children include (a) providing enough trunk support for the child to control the respiratory and speech mechanisms, (b) advancing oral-motor activity, (c) structuring activities that prompt children to produce available sounds more often and volitionally, and (d) providing models and reinforcement that encourage increasing variability of children's sounds. It tends to be a positive sign for their continued vocal development when children continue to learn new sounds or new variations on the sounds they are producing (Marchman, Miller, \& Bates, 1991).

Oller, Eilers, Neal, and Cobo-Lewis (1998) suggested that the late-onset of consonant - vowel babbling might predict later developmental disabilities in speech and language. The ability to vocally imitate may also play a role in a child's ongoing progress in speech development (Clarke, Remington, \& Light, 1986; Romski \& Sevcik, 1996; Yoder \& Layton, 1988). Yoder, Warren, and McCathren (1998) found that the best predictors of speech for young children with developmental disabilities (under 3 years of age) were (a) the number of canonical communication acts in a 5 minute interaction with parent, (b) the rate of protodeclarative use, and (c) the ratio of number of words used versus number of words understood. In this study children needed to produce five or more conventional words in a $15 \mathrm{~min}$. sample to be considered "speakers." It is possible, however, to use fewer or less conventional words and still communicate effectively vocally. Symbolic vocalizations (e.g., quasi-vowels or other sounds used as specific and meaningful referents) may be a functional form of unconventional speech for children who have insufficient control of articulators to produce conventional speech acts. Some of the predictors proposed by Yoder and colleagues may not apply to vocal communication of children with severe motor impairments, because some children may use symbolic vocalizations for effective linguistic communication without ever producing behaviors like canonical babbling. Specific predictions of vocal outcomes for children at risk for being nonspeaking may incorporate different factors specific to this population. 


\section{Where is the best place to start early AAC intervention?}

Early AAC intervention starts with the same communicative functions as does spoken communication. Most children use behavior regulation (controlling someone else's behavior) frequently in beginning communication development (Wetherby, Cain, Yonclas, \& Walker, 1988). Children relying on AAC may first express wants and needs by body postures, gazes, vocalizations, or a wide variety of other gestures, actions, or physical behaviors (Mirenda, Iacono, \& Williams, 1990). As children grow older, more of their communication and conversation revolves around sharing information and commenting (joint attention) or continuing social routines (social interaction), rather than simply requesting wants/needs. Children relying on AAC also begin by expressing wants and needs with multiple available strategies (Reichle et al., 1991). If children's behavioral signals are difficult to interpret, parents may respond meaningfully to behavioral signals for only wants/needs that they can interpret from the environment or other daily routines and schedules (Yoder \& Feagans, 1988). Consequently, many AAC systems focus on requests for wants/ needs much longer than is developmentally or functionally appropriate for children. Children skilled at expressing their wants and needs through behavioral and gestural strategies may find it hard to express joint attention or word labels without more formal symbolic strategies. If children using AAC are already at risk for having restricted communication functions (simple wants/needs requests), practitioners may need to place increased emphasis on promoting other communication forms and functions, such as vocalizing for social interaction or pointing for joint attention (Cress, 2002). For young children who have a limited range of motor behaviors, skills such as eye pointing may be particularly important for responding to questions or requesting objects and activities, as well as the use of simple gaze shifts for the more basic function of attending to activities and/or partner behaviors.

Communicative functions that tend to be acquired early in development may include greetings, protests, requests for attention or objects, and termination of an activity (Reichle, Halle, \& Johnson, 1993). Several of these communicative functions can be fulfilled by spontaneous signals or behaviors and do not require deliberate intent to communicate if they are recognized by communication partners (Rowland \& Schweigert, 1993; Sigafoos, et al., 2000). Children may initially turn away from an unwanted activity, for example, and later may learn a head gesture as a deliberate protest. Requesting "more" of an ongoing activity via hand signal, gesture, vocal or verbal production, signals immediate continuation and can function as a confirmation of a question such as, "Do you want more?" in a concrete way that can prompt later development of specific symbolic behaviors such as those representing "yes" (Iacono, Carter, \& Hook, 1998; Reichle et al., 1991).

Interventionists may mistakenly assume that yes and no are simple concepts that should be introduced first into a child's AAC system, because simple communication aids that allow yes/no responses are introduced to adults with acquired communication disorders (Garrett \& Kimelman, 2000). Using questions that require a yes/no response is an efficient way to prompt a wide variety of communicative messages with a person who only has a limited physical means of response, but only if that person already has a stable understanding of yes/no concepts. Adults with acquired disorders may maintain their understanding of the functions of yes or no because of the automaticity of these responses after years of use, but may often use even this simple strategy incorrectly because of difficulty processing the communication task (Garrett, 1998; Garrett \& Kimelman, 2000). Young children who do not have the benefit of experience in using words with multiple meanings, however, do not tend to use "yes" or "no" with as much success as adults who may have similar levels of expressive vocabulary.

Answering questions that require yes/no responses tends to be a communication skill developed during the toddler years (18 months to 3 years), even for children with typical development (Steffensen, 1978). These words can have a wide variety of meanings and results. From a functional perspective, "yes" or "no" may not mean the same things in any two situations, because the interpretation of those words is dependent upon the question asked. Therefore, even after children begin to use yes and no appropriately, they tend to vary in their success at answering questions that require a yes/ no response across linguistic contexts, and frequently make errors in saying either yes or no when it does not match their communicative intent (e.g., Owens, 2001). The cognitive-linguistic demands associated with answering yes/no questions also challenge the young child's developing ability to compare and match (yes) or negate (no) perceptions of others (Blank, Rose, \& Berlin, 1978). In typically developing children, conventional words or head gestures to indicate yes/no are produced sporadically during the child's first year, and are not sta- 
ble across a variety of situations until well into the second year (Fay, 1984; Steffensen, 1978). By 2 years of age, children tend to have receptive vocabularies of over a hundred words and are starting to combine two symbolic concepts (Fenson, et al., 1993). Yes/ no responses tend to become stable linguistic concepts for children after they have had considerable experience with using language for a variety of purposes.

Furthermore, the over-use of yes/no questions with young children tends to reinforce passive responding rather than active functional communication. Because the specific meaning conveyed by a yes or no depends upon the question asked, the person answering the question has limited control of the communicative message. People who use AAC and rely heavily on their partners using questions that require yes/no responses are dependent upon those partners and their familiarity with topics and questions that are appropriate for a given situation. Therefore, conversation between a speaking person and an individual who uses AAC tends to involve more speaker turns and control, even if the individual who uses AAC is quite skilled (Light, 1988). Finally, children whose most frequent words are yes/no may be infrequent initiators, because these words are not useful for initiating messages. Other communicative functions, such as "more/ all-done" can more effectively serve as both initiations and responses for early communicators.

\section{Is it Necessary to Understand Specific Concepts/ Vocabulary Before That Vocabulary can be Used for Communication?}

It is difficult to determine what concepts/ vocabulary any child actually understands because judgments are made on the basis of her or his performance, which may or may not reflect underlying competence (Miller \& Paul, 1995). Information about comprehension and communicative intent is particularly limited for children who do not use speech (Romski \& Sevcik, 1993). Even judging comprehension in individuals who are skilled in the use of AAC is complicated by elements of partner input, voice output, or demands of language comprehension tasks (Sutton, Soto, \& Blockberger, 2002). Waiting for children to fully demonstrate comprehension of a concept before using words for it would place too much emphasis on the interventionist's limited ability to gauge the extent of a child's comprehension of any given word. Dowden and Marriner (1995) emphasize that AAC intervention can begin before formal assessment is complete, and that assessing lan- guage comprehension is an ongoing and constantly changing process.

Although AAC intervention emphasizes increasing functional communication to accomplish communicative goals, the development of language comprehension and language organization are also important considerations, and, as such, need to be incorporated into children's early AAC systems (Romski \& Sevcik, 1993). AAC strategies such as aided language stimulation (Goosens', Crain, \& Elder, 1992) or the System for Acquiring Language (Romski \& Sevcik, 1996) provide structured methods of facilitating complex symbol output with environmental and partner support of symbol comprehension. The use of increasingly advanced syntactic structures in either spoken or augmented modes relies on children's linguistic competence in relating concepts to each other in systematic ways. Children with symbolic skills can understand new concepts by exploring new symbol displays and activating the voice output for those symbols. They also can notice or interpret partners' prompting cues to infer symbol meaning, or "fast map" symbol meanings from limited exposure and compare known and unknown symbols with probable interpretations (Beukelman \& Mirenda, 1998).

To fully understand the power and appropriateness of vocabulary, young children also need experience in expressing (new) words/concepts and combining them with other linguistic elements for direct communicative purposes. Use of symbolic words and concepts does not have to wait until children understand those concepts, even for typically developing children. Although Piaget emphasized the role of cognitive development in promoting further language development, other researchers, such as $\mathrm{Vy}$ gotsky (1986) have demonstrated that acquisition of a particular cognitive construct does not necessarily precede the productive use of language that represents that construct. Children, for instance, use the word more in very early communication, but only gradually learn that more is a stable property of object relations that is not dependent upon physical appearances. Continued social use of the term and subsequent cognitive development helps the child's internal lexicon approach adult-like status.

Available research suggests that for an individual who uses AAC the language he/she understands and produces may be context-related and differently organized than that of communicators who use speech (Nelson, 1992). As children who use speech learn new words, for example, they are likely to spontaneously produce these words in play or interactions. During fast mapping stages, children who use speech may 
produce words not already in their repertoire that they have learned from incidental exposure (Crais, 1992). On vocabulary checklists, such as the MacArthur Communicative Development Inventory (Fenson et al., 1993), however, parents of children who do not use speech do not have access to unexpected or incidental use of words to guide their report of their children's vocabulary understanding (Ross \& Cress, 2001). Judgments about vocabulary comprehension in these children are usually limited by their unconventional responses to words or specific probes of vocabulary comprehension.

AAC intervention for young children, therefore, needs to include teaching new concepts and words by using them, rather than by expecting a child to first demonstrate understanding of them. Social learning models of language development emphasize the role of routines and scripts in supporting early production of words and phrases that children may not yet understand individually (Bates, O'Connell, \& Shore, 1987). As an example, children may understand that the word peek-a-boo prompts adults to restart a particular interactive game before they comprehend that the same word is also a label for that game and its actions. The experience of the word within the routine context scaffolds lexical development by establishing an activity-based concept to which the label may be attached (Snow, 1989). It would be counterproductive to teach children to say peek-a-boo (or point to the symbol for PEEK A BOO) unless they have had sufficient experience with that word in context (Wood, Lasker, Siegel- Causey, Beukelman, and Ball, 1998). Wood et al. (1998) called this early experience of language concepts "augmenting the message," where the partner enhances the meaning and salience of the word, symbol, or gesture within the immediate context. They also highlighted three additional components of augmented input: facilitating the child's (a) symbol association, (b) memory/recall, and (c) selection of response options.

Waiting until a child demonstrates understanding of what is presented to him or her may promote passive interactions. When children's communication success depends upon adults accepting the completeness or accuracy of the message, children may learn to comply with adult expectations at the expense of expressing their own communicative messages. Basil (1992) reported case studies of children who demonstrated learned helplessness under such adult-directed communicative circumstances. She found that by teaching parents and teachers to reduce conversational dominance they facilitated greater child initiation within conversations. Unfortunately, Down- ing (1988) reported that this adult-focused structure for children's communication is prevalent in schoolage Individualized Education Plan (IEP) goals, where children who do not use speech are systematically taught to respond to adult communication (such as choosing symbols to match an adult model) before they are provided with opportunities to use those symbols themselves for communicative exchanges. A contrasting approach is to introduce children to the active role of speaker and reinforce all active communicative initiations before this passive role is well developed. Carter (2003) provided data to support a conceptual framework for evaluating contexts under which augmented communicators spontaneously initiate and receive responses to their communicative acts within school settings.

\section{What should be done if the child's AAC attempts are inappropriate, confusing or random?}

Children who rely on AAC need to experience the same kinds of feedback and alternatives that typically developing children do for equally confusing or inappropriate communication. Children learn the power and meaning of communication by observing its impact on their environment (Ginsberg \& Opper, 1979). One of the ways that typically developing children explore the appropriateness of communication is by mistakenly or intentionally using socially unacceptable messages, such as initiating taboo topics, teasing, using insults, or swearing. Children who have limited communication strategies need to be provided with similar opportunities to experience the consequences of socially unacceptable messages, as well as help to explore a range of communicative functions and to experience the relative ineffectiveness of these actions on social interactions. Although a child's first communication messages might not include explicit teasing or insults, children with complex communication needs may often initiate messages that are inappropriately timed or directed. For instance, a child with a single switch device saying "more food" might activate that switch for multiple attentional or functional purposes that are not related to the linguistic message. By experiencing different partner responses, the child can gradually learn the contrast between consequences of the "more food" message and a beckoning gesture for attention. When children are producing signals or messages for multiple or ambiguous purposes, they can be helped to disambiguate these messages with alternative strategies for expressing various intents. As an example, a child can be prompted to turn his or her head, if it is in the child's gestural 
repertoire, with increased consistency when protesting something, as a means of disambiguating a general vocalization used for both protest and requesting purposes. Prompting alternative forms of messages is particularly helpful when children communicate messages with challenging behaviors, such as throwing an object to indicate "all done" (Doss \& Reichle, 1991).

Sometimes, communication that begins as random behaviors or signals helps a child to learn the meaning of different messages within their interactional contexts. Children do not necessarily have to understand the meaning or function of their own behaviors to be able to learn from the experience of using those behaviors in ways that are interpreted as communicative within certain contexts. Several studies have demonstrated that non-linguistic contingent responses to children's behaviors promotes their communicative development, even for children who do not yet demonstrate intentional communicative behaviors (Tannock, Girolametto, \& Siegel, 1992; Yoder \& Warren, 1998). For infants and toddlers with multiple developmental delays, the frequency and contingent reinforcement of these pre-linguistic behaviors may be limited (e.g., Yoder, 1987). The Prompt-Free communication strategy developed by Mirenda and Santogrossi (1985) systematically reinforces children's spontaneous behaviors and helps to shape them into intentional behaviors. A child's random activation of a voice output device might be reinforced with the activity requested by that device. The context is structured so that children's spontaneous behaviors have a reasonable likelihood of successfully initiating a message without adult prompting. As children become more deliberate in producing the target behaviors, contextual cues are gradually reduced to increase their independence in initiating communication.

Adults often may be reluctant to over-interpret children's behaviors, particularly if there are no other means of confirming children's messages beyond partner-perceived communication. Parents may ignore communicative messages if they think they have misinterpreted the underlying intent (Yoder, 1987). Children, however, learn to move beyond partnerperceived communication into intentional communication by receiving consistent feedback on the meaning assigned to their behaviors by others in their environment. Wilcox, Bacon, and Shannon (1995) found that when parents received intensive training in recognizing and responding to their children's consistent behaviors, they perceived and responded contingently to more targeted communicative behaviors that had been identified during parent training sessions. By interpreting children's communica- tion as if it is meaningful, children learn to associate meaning with their spontaneous or learned behaviors (Yoder \& Warren, 1998). Restricting children's communication strategies to meet adult expectations can limit children's own understanding of pragmatics and tends to reinforce reliance on adults to interpret and structure their communicative exchanges. If methods of communication that are used inappropriately are removed or restricted, children will have little opportunity to learn how and when such communication is to be used appropriately.

\section{How can communication systems be moved beyond a single word level?}

It can be developmentally appropriate for children who use AAC early to spend some time communicating at a single word level if they are actively learning to expand to multiword utterances. Typically developing children spend a year or more using single words to represent a wide variety of messages across different communicative functions and contexts (Bloom, 1993). A young child might use the same single word cookie to indicate a request (as in want cookie) or comment (as in cookie all gone). By using these single words across multiple contexts, children gradually can build the understanding of object and person relationships in their linguistic system represented in multiple-word utterances (Owens, 2001). Therefore, if children or adults have had insufficient experience with using single words to express their thoughts, spending some time experiencing this level of communication is appropriate. It is important, however, to continue to explore and prompt strategies for multiword utterances during periods of single symbol use.

Single switches, pictures, or gestures can naturally reinforce the direct association between messages and particular behaviors, symbols, or spoken output. Early words are usually learned during routines with functional or interactive goals, in which words have a one-to-one correspondence between meaning and its representation (Bates et al., 1987). Key factors in using single words within these routines include (a) matching messages to functional goals within the interaction, and (b) gradually allowing children opportunities to apply these messages toward additional communicative goals (Snyder- McLean, Solomonson, McLean, \& Sack, 1984). A child might use the message "ball" on a voice output device, for example, only to request a ball within turn-taking games, and then gradually begin to show intent for commenting on the ball's actions using the same message. 
When first expanding single symbols into multiword productions, it is important not to overemphasize the correct use of these symbols or respond to only one idealized production or meaning. When typically developing children expand their spoken word use beyond familiar routines, they may initially make semantic errors, such as over-generalizations, in applying words to related concepts that do not represent the same meanings (e.g., calling all four-legged animals doggie) (Rescorla, 1980). Romski and Sevcik (1989) suggested that these overextensions may not disappear from the language of persons with restricted vocabulary sets as quickly as with typically developing children. One possible explanation is that some children do not experience as many communicative functions for individual messages given physical or social restrictions in activity, and often do not receive meaningful feedback from listeners about their errors (von Tetzchner \& Martinsen, 1992). Therefore, when introducing new vocabulary elements to children's repertoires, it is important to allow the child opportunities to play with the vocabulary and explore new meaning combinations in trial-and- error learning. Adult demonstration and meaningful responses to over-extension errors may be more helpful than soliciting target labels or correcting the child's interpretation directly (Mervis \& Mervis, 1988).

Some of the frustration expressed by partners communicating with children who are restricted to the use of single words may be related not to the vocabulary limitations, but rather to the limited communicative functions or types of messages that are used with the switch/gesture. Multiple word augmented communication relies on simultaneous access to vocabulary that can be combined linguistically to express new concepts and functions. Children's early words often represent such diverse semantic functions as greetings, labels, recurrence (e.g., more), rejection, nonexistence (e.g., "all-gone"), attributes, and possession (Bloom, 1993). Children who do not use speech and are successful language learners often include action, attribute, and relational terms in their early vocabularies (Fried-Oken, 1992). Unfortunately, a majority of messages on communication boards or devices for beginning communicators often represent the single function of behavior regulation (requesting or rejecting objects or actions) (Beukelman \& Mirenda, 1998), and less often reflect commenting, attributions, or possession functions typical of more advanced relational communication (Tomasello \& Farrar, 1984). It is difficult to express more advanced functions and learn word combinations without access to the vocabulary that is combined to create these types of messages. Early communication systems should be adapted frequently for communication situations and should include easy-to-combine concepts for simple semantic relations in the form of adjectives, actions, and possessives (e.g. "my", as well as nouns and verbs.

Children who cannot access more than one switch can also learn to combine a single switch message with other behavioral strategies, such as eye-gaze, gesture, or vocalization, to incorporate these multiple concepts. Children can also combine two to three words through a series of single messages or responses to questions, such as "ball" (response to what?) + "basket" (response to where?) + child's name (response to who?). In these circumstances, it is helpful to provide the child with concrete visual feedback about the meaning of the message that has been constructed through this sequential partner-supported method (Goossens' et al., 1992). As an example, the partner could write or draw the words conveyed by the child's gestures and symbols on a write - erase board for visual feedback as the child indicates them, and then translate the words into a complete English sentence verbally and in writing below the child's utterance for visual language input and prompting.

\section{Are Voice Output Systems Considered Better Than Low-tech Picture Selection Systems?}

People are children's first tools, and learning to effectively control people's actions through any available mode is one of the most powerful lessons for children to learn about communication. The most basic communication between a parent and child is behavioral (e.g., parents responding to children's facial and body signals). Young children are most likely to first understand the communicative potential of their own body as a tool in controlling their environment (Cress, 2001). Successful communication using any other types of tools, such as voice output or picturebased devices, implies experience with basic behavioral (body) strategies (Cress, 2002). Young children tend to signal their internal state with facial expressions or vocalizations and act intentionally towards objects (e.g., reaching, pushing) before they direct those behaviors towards an adult as a tool to obtain a functional goal (Dunst \& Lowe, 1986). Each additional "tool" that is added to this simple body tool set increases the relative complexity of the communicative act and the difficulty of conveying a message successfully. The message and the systems used to represent it are also functional tools that a child learns to control within communication activities. If children are not successful at controlling their own bodies, other peo- 
ple, simple signals, or representations of messages, then using either a voice output or picture-based device for linguistic messages may simply add complexity that can further distance children from the desired communication goals. Multiple design elements, such as selection strategies, auditory feedback, and visual or conceptual organization of language can directly affect learning demands and cognitive load in children's use of AAC systems (Light \& Drager, 2000). Although children can learn to use multiple new strategies across different activities, it is important to introduce only one difficult thing at a time when adding new elements to a child's communication system for a particular message.

The primary benefit of a tool such as a voice output system or a low-tech picture display is the extent to which it enhances interaction between people. For some children, such as those with autism, a communication device can become an interesting object in itself that may actually interfere with using that device for communicative interactions (Mirenda, Wilk, \& Carson, 2000). Success in operating a voice output device is not necessarily associated with equivalent success in understanding its effect in conveying a message. Understanding that any external device represents a child's own communicative message requires cognitive skills in addition to those required for spoken or behavioral forms of communication (Cress, 2001). Confirming that a voice output message matches a child's intended message adds cognitive load over that required for low-tech, behavioral, or gestural communication. In some situations, lowtech pictures may be more direct and simpler than voice output devices for children and their partners to manipulate and understand. In particular, ambulatory children may find even simple lightweight technology with voice output systems difficult to access in some communicative situations (Dowden \& Marriner, 1995).

Experience with using either voice output or picture-based systems in social situations can help infants with disabilities to learn their communicative effects in social contexts. Infants can learn that pushing a switch or touching a symbol can influence other people's behavior (Callaghan, 1999; Rowland \& Schweigert, 2000; Sullivan \& Lewis, 1993). Young infants have demonstrated the use of switches or devices to change aspects of their environment (Behrmann \& Lahm, 1983; Brinker \& Lewis, 1982; Ferrier, Fell, Mooraj, Delta, \& Moscoe, 1996, Swinth, Anson, \& Deitz, 1993). However infants with multiple disabilities may not necessarily transfer understanding of their effect on objects such as switches to under- standing their effect on people, without additional experience and response from partners. Simple practice at cause/effect switch toys may not translate directly into communicative uses of switches, because using switches to influence another person's behavior adds cognitive complexity to the task. If, on the other hand, a child's behavior is inconsistent or unsuccessful in obtaining a partner response (e.g., his or her use of an eye-blink or body tension signal), a more recognizable signal such as a switch-operated voice output device may increase the rate of partner response and help the child associate this response with his or her own intentional behavior.

Voice output systems have particular advantages over non-electronic strategies for some partners or situations. For children who have limited control of their own vocalizations, using voice output or other auditory signals can be used effectively to gain attention from others (Swinth et al., 1993). Similarly, voice output systems can be effective for communicating across distances when the communication partner may not perceive more subtle behavioral messages. When communicating with other children or unfamiliar partners, voice output is often more easily interpreted and understood by partners (Hustad, Morehouse, \& Gutmann, 2002). In addition, voice output systems can provide information to children with complex communication needs about their own messages that may enhance language learning (Romski, Sevcik, \& Adamson, 1999). For instance, children may press an unfamiliar symbol on their voice output device as a strategy to remember or learn new vocabulary. Voice output systems with symbol/ icon cues can also reduce the required memory load inherent in behavioral systems by supporting word finding through recognition rather than retrieval memory. Iacono and Duncum (1995) found that adding voice output to a 2 year old child's sign language system enhanced her single word as well as her multiple word expressions, and was the child's preferred communication modality. There have also been suggestions that early control of sound output, such as rolling over a blanket to produce electronic "babbling," may enhance children's understanding and use of movement/sound relationships (Ferrier et al., 1996).

It is not necessary to wait for children to fully develop their expected skills at motor control, language, or communicative function before adding voice output strategies to their repertoires. Even complex voice output devices can be used for simple messages by early communicators who may gradually expand the range of device features and purposes used for communication. A multi-item dynamic display, for exam- 
ple, may only show two messages at any given point, to allow young children to learn the effectiveness of the device for simple choice making. Early communicators may push voice output switches to learn their effect on the environment and gradually understand their effect on people. Complex keyboards may be fitted with adapted switches as children gradually improve their motor skills. Children may begin using simple technology, such as digitized voice output, and later use this technology for quick or transitory messages as they incorporate more complex technologies for more complex messages.

Voice output systems, therefore, can provide useful augmentation to children's existing communication efforts. Since AAC involves multimodal communication, however, it is not necessary to choose between voice output and low-tech symbols. Most early AAC systems involve elements of both strategies that can be used for different purposes (e.g., voice output for interactions with peers who are prereaders, and picture symbols or behavioral strategies for one-on- one interaction). Case examples of incorporating voice output and low-tech AAC strategies with behavioral AAC strategies for young children with various degrees of communication skills are provided in Cress (2002). Even adults skilled in the use of AAC may use low-tech symbols or gestures in situations where voice output may be relatively inconvenient or inefficient (e.g., a swimming pool). The voice output system and/or picture symbol system will be most successful if children already know how to use basic communication tools such as facial, vocal, or gestural systems that they can activate volitionally and appropriately for communication purposes.

\section{Why Does the Child Seldom Initiate Communica- tion with an AAC System?}

According to Beukelman and Mirenda (1998), "Without participation, there is no one to talk to, nothing to talk about, and no reason to communi-

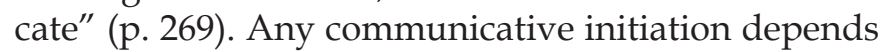
on the opportunities and support for communication, as well as the individual's motivation and skills to convey a particular message. Beukelman and Mirenda's Participation Model emphasizes the critical importance of communication opportunities that are meaningful to children, not just their partners. They also stressed that limited initiation should not be attributed automatically to child-based motivation because motivation is highly context dependent. Dowden and Marriner (1995) suggested considering the phrase, "This child isn't motivated to use the de- vice/book/board" (p.155) as a warning sign to re-examine best practices within the intervention team. Whenever children or adults are not initiating communication using AAC systems, the characteristics of the environment and partner responses must be examined.

Children who rely on AAC may need specific coaching in (a) recognizing pragmatic cues in new or advanced communicative contexts, and (b) responding to communicative breakdowns if their initiations are poorly timed or not understood within the interactions (Calculator, 1988). Some kinds of structured interactions, in which the adult primarily solicits child communicative responses, may not successfully promote initiation. Understanding a message or symbol is very different from knowing how and why to initiate that message, particularly in children who have difficulty recognizing pragmatic cues, such as children with autism (Prizant, Wetherby, \& Rydell, 2000). Simply increasing the size of a child's receptive vocabulary is insufficient to promote communication if he or she has difficulty with initiation.

Even individuals skilled in the use of AAC may need assistance with recognizing communication opportunities or substituting alternative behaviors to repair communication breakdowns (Buzolich \& Lunger, 1995). Because the messages of children who are not yet producing adult-like communication will at times be confusing to partners, children need to learn strategies for modifying their messages in ways that still accomplish the same communication goal. In general, individuals who are successful in using AAC tend to have a variety of methods for resolving communication breakdowns, many of which overlap with strategies used by speaking communicators (Fishman, Timler, \& Yoder, 1985; Brady \& Halle, 2002).

If the outcomes of children's self-initiated communicative attempts are not consistent, reinforcing, prompt, and relevant to the interaction, there will not be enough contextual support for further initiations. Children who can initiate intentional communication, for example, may reduce the frequency of their communication attempts (or increase their use of challenging behaviors) if their efforts receive limited responses (Doss \& Reichle, 1991). In fact, many of the behaviors that may be perceived as learned helplessness may in fact be associated with a failure to actively and systematically plan for eliciting spontaneous initiations in children's environments (Carter, 2002). The relative slowness of most AAC strategies may also influence children's abilities to initiate communication promptly when it is needed or desired. For instance, children who are skilled at creating 
complex messages on voice output systems in dyads with familiar partners may not initiate with partners if there are only brief or limited opportunities available for initiating messages. Furthermore, Carter (2003) found that $87 \%$ of successful acts produced by symbolic communicators happened in the presence of natural routines and cues such as nearness of a desired object or communication partner, rather than structured training situations.

Parents typically carry most of the responsibility for managing conversational interaction until infants are intentional communicators. For instance, parents of young infants with disabilities may comment on a child's spontaneous behavior (such as a vocalization) and accept any recognizable movements or sounds as legitimate child turns (Yoder \& Feagans, 1988). Once children begin to demonstrate intentional communicative behaviors, parents reduce their response to all behaviors and wait or prompt for more initiation from children (Snow, 1995). If parents do not perceive the intentional nature of a child's behavior, they are more likely to continue to take responsibility for initiating and maintaining conversations for that child than they are with children who persist in actively claiming their own communication turns. Children with subtle or variable signals may not consistently be perceived as communicative and, therefore, may maintain passive communication roles longer than do more conventional communicators (Cress, 2002).

Interaction with people who use AAC tends to involve more direction and turns by the speaking partner, who may speak too fast to allow the person to interject using his or her AAC system (Calculator \& Dollaghan, 1982; Light, 1988). People of all ages who use AAC are likely to show more limited types of communicative acts than speaking partners (Light et al., 1985) and spend more conversational time as responders than as initiators (Yoder \& Kraat, 1983). Children with limited expressive strategies, who have few means available to claim conversation turns, are even more likely to participate in conversations using primarily responsive communication patterns. Young children with complex communication needs who use gestures as primary communication strategies, for example, are more likely to be responsive during interactions with adults than is expected for language-age peers on a standardized assessment of communicative and symbolic behavior (Cress et al., 2000).

Improving the initiations of children who rely on AAC may depend on changing the behaviors and activities presented by communication partners, particularly in educational or therapeutic environments
(Calculator \& Jorgensen, 1992; Houghton, Bronicki, \& Guess, 1987). Formal teaching tends to be associated with frequent questions and conversational turns by the speaking partner. If parents and therapists perceive their role in conversations with young children with complex communication needs as promoting language development, they may use more instructional or directive behavior than they do during social conversation with children (Tannock, 1988). This directive behavior of parents of children with disabilities can reflect a functional response to the children's need for guidance in some difficult and challenging communicative tasks, however (Marfo, 1992). Parents can support children's language development when their directive acts follow the children's focus of attention and apparent functional intent (Akhtar, Dunham, \& Dunham, 1991).

In AAC intervention, introducing and using new signals or symbols should be done during natural interactions that follow a child's interest and attention rather than directing his or her attention to strategies outside the interaction contexts. Interaction strategies responsive to children's behaviors tend to facilitate language development better than more didactic/directive strategies. Tomasello and Farrar (1986) demonstrated that 14-month-old children learned new words fastest when labels were introduced as the children were attending to the targeted and labeled objects, rather than when their attention was redirected to the item before labeling it. Therefore, presenting a new symbol or communicative behavior out of context is an inefficient teaching strategy with young children, who may have difficulty shifting attention from the symbol to its distant referent.

Instead, AAC partners can encourage children's initiations by presenting a new symbol, activation, or behavior as an extension of the child's existing communicative behaviors. For instance, if a child typically reaches toward an object to communicate "more," teaching a new symbol or device activation separately from this spontaneous behavior may redirect the child's attention and increase communicative difficulty. Instead, partners can naturally prompt the child (e.g., by holding out the desired object) to initiate their known behavior (e.g., reaching), then model the new behavior for the child to expand the complexity of the action (e.g., touching the picture symbol to the child's outstretched hand before giving the desired object). These kinds of expansions and extensions are widely recommended behaviors in language therapy across different groups. Introducing a new AAC strategy as a response to rather than as a replacement of existing communicative behaviors can 
both reinforce the child's spontaneous initiation and facilitate more rapid learning of that strategy.

\section{SUMMARY}

The introduction of AAC to early communicators need not be as difficult as once thought. Simple adjustments in listener behaviors as well as appreciation for early simple vocalizations or child behaviors can be critical in maximizing an infant/toddler's potential for effective communication later on. Postponing the consideration of AAC strategies when behaviors and physical conditions suggest high risk for delayed or impaired speech can be detrimental to a child's long-term speech and language development. By recognizing factors that serve as erroneous prerequisites to $\mathrm{AAC}$, practitioners can adapt their $\mathrm{AAC}$ service delivery practice to reflect best practice in early AAC for all communicators. AAC systems such as voice output and picture symbols can be incorporated as part of children's earliest communicative interactions to enable them to experience the functions of voice and symbols within interactions. Initial attention to the child's spontaneous intentional behaviors and the adult's contingent responses can make the introduction of additional communication tools successful as experience in the process of communication is established.

Acknowledgements - This paper was supported in part by grant \#K08 DC00102-01A1 from the National Institute on Deafness and other Communicative Disorders, National Institute of Health (NIH), awarded to the first author. The authors thank the Associate Editor, Mark Carter, as well as three anonymous reviewers, for their helpful comments. The authors also appreciate the children, families, and practitioners who have contributed to the insights discussed in this paper.

\section{References}

Akhtar, N., Dunham, F., \& Dunham, P. (1991). Directive interactions and early vocabulary development: The role of joint attentional focus. Journal of Child Language, 18, 41-49.

ASHA (1991). American Speech-Language-Hearing Association Report: Augmentative and alternative communication. ASHA, 33 (Suppl. 5), 9-12.

Basil, C. (1992). Social interaction and learned helplessness in severely disabled children. Augmentative and Alternative Communication, 8, 188-199.

Bates, E., O'Connell, B., \& Shore, C. (1987). Language and communication in infancy. In J. D. Osofsky (Ed.), Handbook of infant development (2nd ed.) (pp. 149-203). New York, NY: John Wiley \& Sons.

Behrmann, M., \& Lahm, L. (1983). Critical learning: Multiply handicapped babies get on-line. In M. Behrmann \& L. Lahm (Eds.), Proceedings of the National Conference on the
Use of Microcomputers in Special Education. Hartford, CT: ERIC.

Beukelman, D. R., \& Mirenda, P. (1998). Augmentative and alternative communication: Management of severe communication disorders in children and adults (2nd ed.). Baltimore: Paul H. Brookes.

Billeaud, F. P. (1998). Role of the speech-language pathologist in the neonatal intensive care unit: Preemies, micropreemies, and medically fragile infants. In F. P. Billeaud (Ed.), Communication disorders in infants and toddlers: Assessment and intervention (2nd ed.) (pp. 85-100). Boston: Butterworth-Heinemann.

Blank, M., Rose, S., \& Berlin, L. (1978). The language of learning: The preschool years. Orlando, FL: Grune \& Stratton.

Bloom, L. (1993). The transition from infancy to language: Acquiring the power of expression. Cambridge, UK: Cambridge University Press.

Bradford, A., \& Dodd, B. (1996). Do all speech-disordered children have motor deficits? Clinical Linguistics $\mathcal{E}$ Phonetics, 10, 77-101.

Brady, N.C. (2000). Improved comprehension of object names following voice output communication aid use: Two case studies. Augmentative and Alternative Communication, 16, 197-204.

Brady, N. C., \& Halle, J. W. (2002). Breakdowns and repairs in conversations between beginning AAC users and their partners. In J. Reichle, D. Beukelman, \& J. Light (Eds.), Implementing an augmentative communication system: Exemplary strategies for beginning communicators (pp. 219-272). Baltimore: Paul H. Brookes.

Brady, N. C., McLean, J. E., McLean, L. K., \& Johnston, S. (1995). Initiation and repair of intentional communication acts by adults with severe to profound cognitive disabilities. Journal of Speech and Hearing Research, 38, 1334-1348.

Brinker, R. P., \& Lewis, M. (1982). Making the world work with microcomputers: A learning prosthesis for handicapped infants. Exceptional Children, 49(2), 163-170.

Buzolich, M. J., \& Lunger, J. (1995). Empowering system users in peer training. Augmentative and Alternative Communication, 11, 37-48.

Calculator, S. N. (1988). Promoting the acquisition and generalization of conversational skills by individuals with severe disabilities. Augmentative and Alternative Communication, 4, 94-103.

Calculator, S., \& Dollaghan, C. (1982). The use of communication boards in a residential setting: An evaluation. Journal of Speech and Hearing Research, 47, 181-187.

Calculator, S. N., \& Jorgensen, C. M. (1992). A technical assistance model for promoting integrated communication supports and services for students with severe disabilities. Seminars in Speech and Language, 13, 99- 110.

Callaghan, T. C. (1999). Early understanding and production of graphic symbols. Child Development, 70, 1314-1324.

Carter, M. (2002). Communicative spontaneity in individuals with high support needs: An exploratory consideration of causation. International Journal of Disability, Development, and Education, 49, 225-242.

Carter, M. (2003). Communicative spontaneity of children with high support needs who use augmentative and alternative communication systems II: Antecedents and effectiveness of communication. Augmentative and Alternative Communication, 19, 155-169. 
Clarke, S., Remington, B., \& Light, P. (1986). The role of referential speech in sign learning by mentally retarded children: A comparison of total communication and signal-one training. Journal of Applied Behavior Analysis, 21, 419-426.

Crais, E. (1992). Fast-mapping: A new look at word learning. In R. Chapman, (Ed.), Processes in language acquisition and disorders (pp. 159-185). St. Louis, MO: Mosby.

Cress, C., \& Ball, L. (1998). Strategies for promoting vocal development in young children relying on AAC: Three case illustrations. Proceedings of the 21st Annual RESNA Conference, Minneapolis, MN.

Cress, C. (2001). A communication "tools" model for AAC intervention with early communicators. Proceedings of the 24th Annual RESNA Conference, Reno NV.

Cress, C. (2002). Expanding children's early augmented behaviors to support symbolic development. In J. Reichle, D. Beukelman, \& J. Light (Eds.), Implementing an augmentative communication system: Exemplary strategies for beginning communicators (pp. 219-272). Baltimore: Paul H. Brookes.

Cress, C., Shapley, K., Linke, M., Clark, J., Elliott, J., Bartels, K., Aaron, E. (2000) Characteristics of intentional communication in young children with physical impairments. Presentation at the 9th Biennial ISAAC International Conference on AAC, Washington, DC: ISAAC.

Culp, D. (1989). Developmental apraxia and augmentative or alternative communication: A case example. Augmentative and Alternative Communication, 5, 27-34.

Cumley, G. (1997) Introduction of an augmentative and alternative modality: Effects on the quality and quantity of communication interactions of children with severe phonological disorders. Unpublished doctoral dissertation, University of Nebraska, Lincoln.

Doss, L. S., \& Reichle, J. (1991). Replacing excess behavior with an initial communicative repertoire. In J. Reichle, J. York, \& J. Sigafoos (Eds.), Implementing augmentative and alternative communication: Strategies for learners with severe disabilities. Baltimore: Paul H. Brookes.

Dowden, P. A., \& Marriner, N. A. (1995). Augmentative and alternative communication: Treatment principles and strategies. Seminars in Speech and Language, 16, 140-158.

Downing, J. (1988). Active versus passive programming: A critique of IEP objectives for students with the most severe disabilities. The Journal of the Association for Persons with Severe Handicaps, 13, 197-201.

Dunst, C., \& Lowe, L. W. (1986). From reflex to symbol: Describing, explaining and fostering communicative competence. Augmentative and Alternative Communication, 2, 11-18.

Fay, W.(1984). Yes/No answers and the verbally delayed child. Topics in Early Childhood Special Education, 4, 73-81.

Fenson, L., Dale, P. S., Reznick, J. S., Thal, D., Bates, E., Hartung, J. P., et al. (1993). MacArthur Communicative Development Inventories. San Diego: Singular Publishing.

Ferrier, L. J., Fell, H. J., Mooraj, Z., Delta, H., \& Moscoe, D. (1996). Baby-babble blanket: Infant interface with automatic data collection. Augmentative and Alternative Communication, 12, 110-119.

Fishman, S., Timler, G., \& Yoder, D. E. (1985). Strategies for the prevention and repair of communication breakdown in interactions with communication board users. Augmentative and Alternative Communication, 1, 38-51.

Fried-Oken, M. (1992). An initial vocabulary for nonspeaking preschool children based on developmental and environmental language scores. Augmentative and Alternative Communication, 8, 41-56.

Garrett, K. (1998). Adults with severe aphasia. In D. Beukelman \& P. Mirenda (Eds.), Augmentative and alternative communication: Management of severe communication disorders in children and adults 2nd ed., (pp. 465-500). Baltimore, MD: Paul H. Brookes.

Garrett, K. L., \& Kimelman, M. D. Z. (2000). AAC and aphasia: Cognitive-linguistic considerations. In D. R. Beukelman, K. M. Yorkston, \& J. Reichle (Eds.), Augmentative and alternative communication for adults with acquired neurologic disorders. Baltimore, MD: Paul H. Brookes.

Ginsberg, H., \& Opper, S. (1979). Piaget's theory of intellectual development (2nd ed.). Englewood Cliffs, NJ: Prentice-Hall.

Glennen, S., \& McPartland, L. (1999, November). But won't they stop talking? Speech development after AAC implementation. Paper presented at the 74th annual conference of the American Speech-Language-Hearing Association, San Francisco, CA.

Gobbi, L., Cipani, E., Hudson, C., \& Lapenta-Neudeck, R. (1986). Developing spontaneous requesting among children with severe retardation. Mental Retardation, 24, 357-363.

Goossens', C. (1989). Aided communication intervention before assessment: A case study of a child with cerebral palsy. Augmentative and Alternative Communication, 5, 14-26.

Goossens', C., Crain, S. \& Elder, P. (1992). Engineering the classroom environment for interactive symbolic communication: An emphasis on the developmental period, 18 months to five years. Wauconda, IL: Don Johnston Developmental Equipment, Inc.

Gur-Arie, P. (2003). Prerequisites for a school-based AAC evaluation. ADVANCE for Speech-Language Pathologists and Audiologists, January 20, 2003, p. 5.

Hanzlik, J. R. (1990). Nonverbal interaction patterns of mothers and their infants with cerebral palsy. Education and Training in Mental Retardation, 25, 334-343.

Houghton, J., Bronicki, G. J. B., \& Guess, D. (1987). Opportunities to express preferences and make choices among students with severe disabilities in classroom settings. The Journal of the Association for Persons with Severe Handicaps, $12,18-27$.

Hustad, K. C., Morehouse, T. B., \& Gutmann, M. (2002). AAC strategies for enhancing the usefulness of natural speech in children with severe intelligibility challenges. In J. Reichle, D. Beukelman, \& J. Light (Eds.), Implementing an augmentative communication system: Exemplary strategies for beginning communicators (pp. 433-452). Baltimore: Paul H. Brookes.

Iacono, T., Carter, M., \& Hook, J. (1998). Identification of intentional communication in students with severe and multiple disabilities. Augmentative and Alternative Communication, 14, 102-114.

Iacono, T. A., \& Duncum, J. E. (1995). Comparison of sign alone and in combination with an electronic communication device in early language intervention: Case study. Augmentative and Alternative Communication, 11, 249-259.

Kahn, J. V. (1981). A comparison of sign and verbal language training with nonverbal retarded children. Journal of Speech $\mathcal{E}$ Hearing Research, 46, 113-119.

Kangas, K. A. \& Lloyd, L. (1988). Early cognitive skills as prerequisites to augmentative and alternative communication 
use: What are we waiting for? Augmentative and Alternative Communication, 4, 211-221.

Lasker, J. P., \& Bedrosian, J. L. (2000). Acceptance of AAC by adults with acquired disorders. In D. R. Beukelman, K. M. Yorkston, \& J. Reichle (Eds.), Augmentative and alternative communication for adults with acquired neurologic disorders. Baltimore: Paul H. Brookes.

Levin, K. (1999). Babbling in infants with cerebral palsy. Clinical Linguistics and Phonetics, 13, 249-267.

Light, J. (1988). Interaction involving individuals using augmentative and alternative communication systems: State of the art and future directions. Augmentative and Alternative Communication, 2, 98-107.

Light, J., \& Drager, K (2000). Improving the design of AAC technologies for young children. Presentation at the International Society for Augmentative and Alternative Communication conference, Washington, DC: ISAAC.

Light, J., Collier, B., \& Parnes, P. (1985). Communication interaction between young nonspeaking physically disabled children and their caretakers: Part 1: Discourse patterns. Augmentative and Alternative Communication, 1, 63-74.

Light, J., Roberts, B., DiMarco, R., \& Greiner, N. (1998). Augmentative and alternative communication to support receptive and expressive communication for people with autism. Journal of Communication Disorders, 31, 153-180.

Locke, J. L. (1996). Why do infants begin to talk? Language as an unintended consequence. Journal of Child Language, 23, 251-268.

MacDonald, E. T. (1980). Early identification and treatment of children at risk for speech development. In R. L. Schiefelbusch (Ed.), Nonspeech language and communication: Analysis and intervention. (pp. 49-80). Baltimore: University Park Press.

Mar, H. \& Sall, N. (1999). Profiles of the expressive communication skills of children and adolescents with severe cognitive disabilities. Evaluation and Training in Mental Retardation and Developmental Disabilities, 34, 77-89.

Marchman, V. A., Miller, R., \& Bates, E. A. (1991). Babble and first words in children with focal brain injury. Applied Psycholinguistics, 12, 1-22.

Marfo, K. (1992). Correlates of maternal directiveness with children who are developmentally delayed. American Journal of Orthopsychiatry, 62, 219-233.

McCune, L., Kearney, B., \& Checkoff, M. (1989). Forms and functions of communication by children with Down syndrome and nonretarded children with their mothers. In S. von Tetzchner, L. S. Siegel, \& L. Smith (Eds.), The social and cognitive aspects of normal and atypical language development (pp. 113-127). New York: Springer-Verlag.

Mcllvane, W. J., Bass, R. W., O'Brien, J. M., Gerovac, B. J., \& Stoddard, L. T. (1984). Spoken and signed naming of foods after receptive exclusion training in severe retardation. Applied Research in Mental Retardation, 5, 1-27.

Mervis, C., \& Mervis, C. (1988). Role of adult input in young children's category evolution: I. An observational study. Journal of Child Language, 15, 257-272.

Millar, D., Light, J., \& Schlosser, R. (2000, November). The impact of augmentative and alternative communication (AAC) on natural speech development: A meta-analysis. Paper presented at the 75th annual conference of the American Speech-Language Hearing Association, Washington, DC.

Miller, J., \& Paul, R. (1995). The clinical assessment of language comprehension. Baltimore, MD: Paul H. Brookes.

Mirenda, P. (1998). Intervention techniques for functional communication training: A research review. Paper presented at the 8th Biennial Conference of the International Society for Augmentative and Alternative Communication, Dublin, Ireland: ISAAC.

Mirenda, P., \& Santogrossi, J. (1985). A prompt-free strategy to teach pictorial communication system use. Augmentative and Alternative Communication, 1, 143-50.

Mirenda, P., Iacono, T., \& Williams, R. (1990). Communication options for persons with severe and profound disabilities: State of the art and future directions. The Journal of the Association for Persons with Severe Handicaps, 15, 3-21.

Mirenda, P., Wilk, D., \& Carson, P. (2000). A retrospective analysis of technology use patterns of students with autism over a five-year period. Journal of Special Education Technology, 15, 5-15.

Nelson, N. W. (1992). Performance is the prize: Language competence and performance among AAC users. Augmentative and Alternative Communication, 8, 3-18.

Oller, D. K., Eilers, R. E., Neal, A. R., \& Cobo-Lewis, A. B. (1998). Late onset canonical babbling: A possible early marker of abnormal development. American Journal on Mental Retardation, 103, 249-263.

Owens, R. (2001). Language development: An introduction (5th ed.). New York, NY: Macmillan Publishing.

Prizant, B. M., Wetherby, A. M., \& Rydell, P. J. (2000). Communication intervention issues for children with autism spectrum disorders. In A. M. Wetherby \& B. M. Prizant (Eds.), Autism spectrum disorders: A transactional developmental perspective (pp. 193-224). Baltimore: Paul H. Brookes.

Reichle, J., Beukelman, D., \& Light, J. (2002). Implementing an augmentative communication system: Exemplary strategies for beginning communicators. Baltimore: Paul H. Brookes.

Reichle, J, Halle, J., \& Johnson, S. (1993). Developing an initial communicative repertoire: Applications and issues for persons with severe disabilities. In A. P. Kaiser \& D. B. Gray (Eds.), Enhancing children's communication: Research foundations for intervention (pp. 105-138). Baltimore: Paul H. Brookes.

Reichle, J., York, J., \& Sigafoos, J. (1991). Implementing augmentative and alternative communication: Strategies for learners with severe disabilities. Baltimore: Paul H. Brookes.

Rescorla, L. (1980). Overextension in early language development. Journal of Child Language, 7, 321-335.

Romski, M. A., \& Sevcik, R. A. (1989). An analysis of visualgraphic symbol meanings for two nonspeaking adults with severe mental retardation. Augmentative and Alternative Communication, 5, 109-114.

Romski, M. A., \& Sevcik, R. A. (1993). Language comprehension: Considerations for augmentative and alternative communication. Augmentative \& Alternative Communication, 9, 281-285.

Romski, M. A., \& Sevcik, R. A. (1996). Breaking the speech barrier: Language development through augmented means. Baltimore: Paul H. Brookes.

Romski, M., Sevcik, R., \& Adamson, L. (1999). Communication patterns of youth with mental retardation with and without their speech-output communication devices. American Journal of Mental Retardation, 104, 249-259.

Romski, M., Sevcik, R. A., Adamson, L. B., Williams, S., Colbert, N., \& Morgan, V. (2001). Communication profiles of tod- 
dlers with severe developmental disabilities. Poster session presentation at the 76th annual conference of the American Speech-Language Hearing Association, Washington, DC.

Romski, M. A., Sevcik, R. A., Reumann, R., \& Pate, J. L. (1989). Youngsters with moderate or severe retardation and severe spoken language impairments. I: Extant communication patterns. Journal of Speech and Hearing Disorders, 54, 366-373.

Ross, B. R., \& Cress, C. J. (2001, November). Comparison of receptive language assessment tools for young non-speaking children. Presentation at the 76th annual conference of the American Speech-Language Hearing Association, New Orleans, LA.

Rowland, C., \& Schweigert, P. (1993). Analyzing the communication environment to increase functional communication. The Journal of the Association for Persons with Severe Handicaps, 18, 161-176.

Rowland, C., \& Schweigert, P. (2000). Tangible symbols, tangible outcomes. Augmentative and Alternative Communication, $16,61-78$.

Shane, H. C., \& Bashir, A. S. (1980). Election criteria for the adoption of an augmentative communication system: Preliminary considerations. Journal of Speech and Hearing Disorders, 45, 408-414.

Siegel, E. B., \& Cress, C. J. (2002). Overview of the emergence of early AAC behaviors: Progression from communicative to symbolic skills. In J. Reichle, D. Beukelman, \& J. Light (Eds.), Implementing an augmentative communication system: Exemplary strategies for beginning communicators (pp. 219272). Baltimore: Paul H. Brookes.

Sigafoos, J., Woodyatt, G., Keen, D., Tait, K., Tucker, M., Roberts-Pennell, D., \& Pittendreigh, N. (2000). Identifying potential communicative acts in children with developmental and physical disabilities. Communication Disorders Quarterly, 21, 77-86.

Silverman, F. H. (1995). Communication for the speechless (3rd ed). Needham Heights, MA: Simon \& Schuster.

Snow, C. (1989). Understanding social interaction and language acquisition: Sentences are not enough. In M. Bernstein \& J. Bruner (Eds.), Interaction in human development (pp. 83-103). Hillsdale, NJ: Lawrence Erlbaum Associates.

Snow, C. (1995). Issues in the study of input: Fine-tuning, universality, individual and developmental differences and necessary causes. In P. Fletcher and B. MacWhinney (Eds.), Handbook of child language (pp. 180-193). Cambridge, MA: Basil Blackwell.

Snyder-McLean, L., Solomonson, B., McLean, J., \& Sack, S. (1984). Structuring joint action routines: A strategy for facilitating communication and language development in the classroom. Seminars in Speech and Language, 5, 213-228.

Steffensen, M. S. (1978). Satisfying inquisitive adults: Some simple methods of answering yes/no questions. Journal of Child Language, 5, 221-236.

Sullivan, M., \& Lewis, M. (1993). Contingency, means-end skills, and the use of technology in infant intervention. Infants and Young Children, 5, 58-77.

Sutton, A., Soto, G., \& Blockberger, S. (2002). Grammatical issues in graphic symbol communication. Augmentative and Alternative Communication, 18, 192-204.

Swinth, Y., Anson, D., \& Deitz, J. (1993). Single-switch computer access for infants and toddlers. The American Journal of Occupational Therapy, 47, 1031-1038.
Tannock, R. (1988). Mothers' directiveness in their interactions with their children with and without Down syndrome. American Journal of Mental Retardation, 93, 154-165.

Tannock, R., Girolametto, L. \& Siegel, L. S. (1992). Language intervention with children who have developmental delays: Effects of an interactive approach. American Journal on Mental Retardation, 97, 145-160.

Tomasello, M., \& Farrar, M. J. (1984). Cognitive bases of lexical development: Object permanence and relational words. Journal of Child Language, 11, 477-493.

Tomasello, M., \& Farrar, M. J. (1986). Joint attention and early language. Child Development, 57, 1454-1463.

Vanderheiden, G. C., \& Lloyd, L. (1986). Communication systems and their components. In S. Blackstone (Ed.), Augmentative Communication: An introduction (pp. 49-162). Rockville, MD: American Speech-Language-Hearing Association.

von Tetzchner, S., \& Martinsen, H. (1992). Introduction to symbolic and augmentative communication. London: Whurr.

Vygotsky, L. (1986). Thought and Language. Cambridge, MA: MIT Press.

Wetherby, A. M., Cain, D. H., Yonclas, D. G., \& Walker, V. G. (1988). Analysis of intentional communication of normal children from the prelinguistic to the multiword stage. Journal of Speech and Hearing Research, 31, 240-252.

Wetherby, A., Warren, S., \& Reichle, J. (1998). Transitions in prelinguistic communication. Baltimore, MD: Paul $\mathrm{H}$. Brookes.

Wilcox, M. J., Bacon, C. K., \& Shannon, M.S. (1995). Prelinguistic intervention: Procedures for young children with disabilities. Presentation at the 70th annual conference of the American Speech-Language-Hearing Association, Orlando, FL.

Wood, L., Lasker, J., Siegel-Causey, E., Beukelman, D., \& Ball, L. (1998). Input framework for augmentative and alternative communication. Augmentative and Alternative Communication, 14, 261-267.

Yoder, D., \& Kraat, A. (1983). Intervention issues in nonspeech communication. In J. Miller, D. Yoder, \& R. L. Schiefelbusch (Eds.), Contemporary Issues in Nonspeech Communication. ASHA Reports, 12, 27-51. Rockville, MD: American Speech-Language-Hearing Association.

Yoder, P. (1987). Relationship between degree of infant handicap and clarity of infant cues. American Journal of Mental Deficiency, 91, 639-641.

Yoder, P., \& Feagans, L. (1988). Mothers' attributions of communication to prelinguistic behavior of developmentally delayed and mentally retarded infants. American Journal of Mental Retardation, 93, 36-43.

Yoder, P, \& Layton, T. (1988). Speech following sign language training in autistic children with minimal verbal language. Journal of Autism and Developmental Disorders, 18, 217-229.

Yoder, P., \& Warren, S. (1998). Maternal responsivity predicts the prelinguistic communication intervention that facilitates generalized intentional communication. Journal of Speech, Language, Hearing Research, 41, 1207-1219.

Yoder, P. J., Warren, S. F., \& McCathren, R. B. (1998). Determining spoken language prognosis in children with developmental disabilities. American Journal of Speech Language Pathology, 7, 77-87. 


\section{Appendix A. Brief Answers to Nine Common Questions about AAC and Early Intervention}

1. How early can AAC interventions begin? what prerequisites are necessary?

- Communication starts with interaction and the earliest behaviors of children - there are no prerequisites.

- Previous research that attempted to assign prerequisites to AAC was only considering symbolic forms of communication.

- Basic AAC includes behaviors, gestures, cooperative actions, and sounds, and does not depend upon controlling complex systems or devices. These early skills do facilitate the gradual development of more complex skills.

See: Beukelman and Mirenda, (1998); Dunst and Lowe, (1986); Kangas and Lloyd (1988).

\section{Will the use of AAC interfere with a child's vocal} development?

- Children will use the quickest, most effective, and most accessible means available to communicate: Speech beats any other AAC system, if it is available to the child.

- Because AAC includes all communication methods, AAC intervention also addresses improving functional verbal skills.

- Available research indicates that AAC facilitates spoken language by increasing interaction, language skills, and/or providing a voice output model for speech.

See: Cumley (1997); Glennen and McPartland (1999); Millar, Light, and Schlosser (2000).

\section{Will this child talk?}

- Talking isn't an either/or question, and labeling a child as "non-speaking" does not indicate that they cannot use speech for some types of communication.

- Children who are having difficulty controlling the muscles involved in speech or respiration, or who have other neurological or cognitive limitations that affect speech and language, are at risk for not developing speech that is intelligible to all listeners.

- Young children's motor systems are still developing in ways that cannot be predicted, and the first three years of life are too early an age to give up on further improvement in speech skills.

- Almost all children who can produce a voice will use sounds in some ways to communicate some mes- sages that can be understood by partners.

- When children continue to learn new sounds or new variations on the sounds they are producing, that is a positive sign for their continued vocal development.

See: Cress and Ball (1998); Romski and Sevcik (1996); Yoder, Warren and McCathren (1998).

4. Where is the best place to start early AAC intervention?

- AAC intervention begins with the same early functions as verbal communication. Early communication functions may include greetings, protests, requests for attention or objects, more/all done. The child need not begin by learning to indicate yes/no.

- Yes/no tends to be a later-developing skill, since those words can have a wide variety of meanings and results. Also, prompts for using yes/no tend to encourage passive responding rather than active communication.

See: Cress (2002); Iacono, Carter, and Hook (1998); Reichle, York, and Sigafoos (1991).

5. Is it necessary to understand specific concepts/vocabulary before that vocabulary can be used for communication?

- It's difficult to tell how much any child understands language, because all we can judge is the performance. An AAC user's language may be contextrelated and differently organized from speaking persons.

- New concepts/words should be taught by using them, not by expecting a child to first demonstrate understanding of them and promoting passive interaction.

- Recognizing and pointing to symbols in response to questions is a very different skill from initiating a new idea with those symbols in conversation.

See: Nelson (1992); Romski and Sevcik (1993); Wood et al. (1998).

6. What should be done if the child's AAC attempts are inappropriate, confusing or random?

- Children relying on AAC need to experience the same kinds of feedback and alternatives that verbal children receive for equally annoying or inappropriate communication.

- Sometimes communication that begins as "random" helps a child learn the meaning of messages. 
See: Doss and Reichle (1991); Mirenda and Santogrossi (1985).

7. How can communication systems be moved beyond a single word level?

- Children need opportunities to communicate more than single concept messages such as operating toys, routine productions (e.g. saying ABCs, singing songs), or making single requests.

- Children using AAC need to have experience in using single words or symbols for different functions (e.g., saying bye-bye as a greeting or stop), as well as being provided access to different words/ symbols for a variety of functions.

- Symbolic AAC communicators also need access to concepts that can be combined, which may involve gestures like pointing or eye gaze to provide the second concept in a single word/symbol message.

See: Goossens', Crain, and Elder (1992); SnyderMcLean et al. (1984).

8. Are voice output systems considered better than low-tech picture selection systems?

- Successful use of either voice output or low-tech systems relies upon experience at being an effective communicator, and both voice and low-tech communication systems can add cognitive load to interactions.
- Many adults skilled in the use of AAC prefer to use low-tech systems because of the directness of interaction with listeners, flexibility, simplicity, reliability, and portability/accessibility.

- Voice output systems have some advantages in gaining attention, communicating across distances, being generally understandable, and providing information to the user. Voice output systems can be introduced in simple ways for beginning communicators

See: Cress (2001); Dowden and Marriner (1995); Iacono and Duncum (1995); Light and Drager (2000).

9. Why does the child seldom initiate communication with an AAC system?

- Spontaneous initiation of communication may be more a function of the activities and environment for interacting than an inherent characteristic of any individual.

- It is essential that children have someone to talk to, something to talk about and a reason to communicate.

- Providing a means to communicate needs to coincide with adaptations in the environment so that partners present opportunities for communicative exchanges and respond to children's meaningful behaviors.

See: Beukelman and Mirenda (1998); Calculator and Jorgensen (1992); Carter (2002); Houghton, Bronicki, and Guess (1987). 